\title{
Responses of Young Toads to Light and
} Contact

By C. F. CURTIS RILEY

Reprinted from the Journal of Animal Behavior May-June, I9r3, vol. 3 , no. 3, pp. I79-2I4. 



\title{
RESPONSES OF YOUNG TOADS TO LIGHT AND CONTACT ${ }^{1}$
}

\author{
C. F. CURTIS RILEY
}

One figure

CONTENTS Page

I. Introduction . . . . . . . . . . . . . . . . . . . . 179

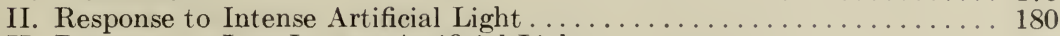

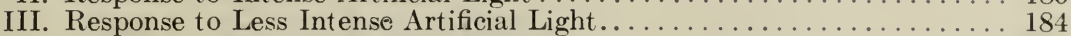

IV. Response to Strong Diffuse Daylight...................... 186

V. Response to Weak Diffuse Daylight . . . . . . . . . . . . . . . . . 189

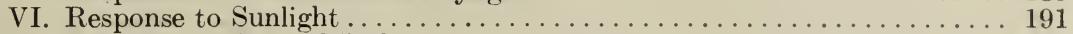

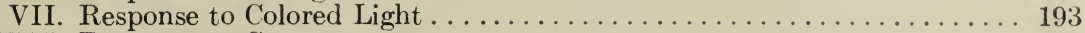

VIII. Response to Contact... . . . . . . . . . . . . . . . . . . . . . . . 198

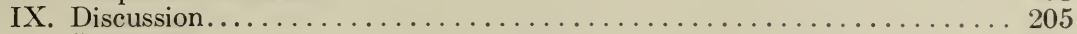

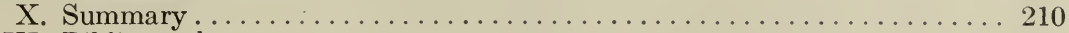

XI. Bibliography ................................ 213

\section{INTRODUCTION}

Several years' ago the opportunity arose to investigate the responses of a number of young toads, Bufo americanus Le Conte. ${ }^{2}$ The toads averaged about $\mathrm{I} 4 \mathrm{~mm}$. in length. The animals were kept in a glass aquarium jar in the laboratory, the vessel being placed $3 \mathrm{~m}$. from an east window in a shaded place. A piece of filter paper, dampened with water, was placed in the bottom of the jar in order to keep the animals moist. They were fed each day on small flies and mosquitoes.

As the toads displayed marked responses to light and contact, it was decided to commence experimentation with photic and contact stimuli. The entire series of experiments were carried on in a dark room at an approximate temperature of $22^{\circ} \mathrm{C}$. For experimental purposes, a glass dish with parallel sides was used. The dimensions of the vessel were $60 \times 25 \times 6 \mathrm{~cm}$., inside measurements. In order to eliminate the effects of reflection, the experimentation trough was painted a dull black on the inside with the exception of the two ends; each of which was covered with a strip

\footnotetext{
${ }^{1}$ Contributions from the Zoölogical Laboratory, University of Illinois, under the direction of Henry B. Ward, No. 21.

2 The experimental work was done at Ann Arbor, Michigan, in the summer of 1904, and the first draft of the paper was made the following year. The literature was reviewed, the paper recast and entirely rewritten at Urbana, Illinois, during the winter of 1912-1913.
} 
of paper having a dead black finish. This paper was so arranged that it could be readily removed at either end, thus permitting the rays of light to enter.

Unfortunately, the writer was unable either to complete the work on the responses to photic and contact stimuli, or to commence any experiments on other forms of reaction work. Through an oversight, the water was allowed to dry up in the jar containing the toads, and the next time they were needed for experimentation purposes they were found to be dead. As it was not possible, at the time, to obtain any more material, and as the opportunity to complete the work has not presented itself since then, it was thought best to publish in a brief form the results of the experiments incomplete as they are. The writer hopes, at some future time, to continue the work outlined in this paper in far more detail and to supplement it with experiments on responses to other forms of stimuli.

Thanks are due to Miss F. J. Dunbar of the Zoölogical Department of the University of Michigan, who kindly collected the amphibians used in these experiments. Mr: S. A. Rowland, of the Physics Department of the University of Illinois, calculated the intensity of the illumination within the field of experimentation employed in this work. His assistance is gratefully acknowledged. The writer also desires to express his appreciation of the criticisms and encouragement given by Doctor C. C. Adams of the University of Illinois.

\section{RESPONSE TO INTENSE ARTIFICIAL LIGHT}

The first experiments undertaken were with reference to intense artificial light as a source of stimuli. The light employed for this reaction work was obtained from the electric arc of a Thomson " $90^{\circ}$ carbon" projection lantern. The current passed from the electric lighting circuit through a rheostat, and from there to the lantern. The current was direct with an approximate voltage of $2 \mathrm{I}$. Within the fie.d of experimentation the illumination was approximately ı,,००० ca. m. In order to eliminate the effect of the heat rays, the light was allowed to filter through a cell containing distilled water. Having placed the toads in the glass dish, it was then mored into the beam of light that emerged from the lantern. In order to prevent the organisms from becoming unnaturally dry during 
experimentation, the trough was immersed in cool water from time to time, thus keeping the vessel cool and moist.

When the dish is placed in the beam of light, it is noticed that the toads are scattered promiscuously throughout the entire length of the vessel. The first demonstrative movement is a decided orientation. All the animals that are facing the light immediately turn around until their heads are pointing directly away from the source of illumination. The orientation is of such a nature that the longitudinal axes of their bodies become parallel with the rays of light. Those individuals which are facing away from the source of illumination, in the first instance, are already commencing to jump away from the light. After all the toads have completed the orienting reaction, there is a general movement towards that end of the dish farthest from the source of light. The animals jump rapidly toward the extremity of the vessel. The pauses between the jumps are very brief, in many instances barely extending over a second of time. Orientation with the longitudinal axis of the body parallel with the incoming rays is retained while the organisms travel the entire length of the dish. After reaching the end of the receptacle, the toads usually remain oriented with their heads touching the glass. If they are left in this position for some time, many of the individuals climb up the perpendicular end of the vessel as if to move away as far as possible from the source of illumination. Those that climb to the top are not in the most intense glare of the prejection lantern, their elevated position placing them a little above the strong central beam of light. Possibly this movement may be due, in part, to response to contact stimuli. The dish is now turned around until the end where the animals are congregated is again brought nearest to the light. Those animals clinging to the upright end of the vessel quickly drop to the bottom. All the toads promptly perform the reaction of orientation and jump rapidly to the far end of the trough as in the former instance. This reversing of the dish is continued for about eight trials and the animals respond promptly each time to the photic stimuli, the response being as previously described.

Some experiments on the influence of intense light upon the swimming responses of the young toads were also undertaken. 
Water with a temperature approximately of $22^{\circ} \mathrm{C}$. is poured into the glass receptacle to a depth of $4 \mathrm{~cm}$. The animals are then placed in the water and the vessel moved into the beam of light emerging from the projection lantern. The organisms immediately orient themselves with the longitudinal axis of the body parallel to the rays of light. Complete orientation is quickly followed by every animal swimming vigorously away from the source of illumination to the extremity of the dish. The young toads retain their precision of orientation as they move through the water for the entire length of the vessel. After all the animals have assembled at the end of the dish, it is turned around, thus placing the organisms again nearest the source of light. The animals as before respond promptly, swimming to the far end of the vessel. In this connection it may be mentioned that Torelle (I903, p. 473) while engaged with some very interesting experiments, demonstrated that in water Rana virescens and Rana clamata move to the illuminated end of a glass trough. Diffuse daylight was used in these experiments.

Many consecutive experiments of the nature of the above were performed, the toads orienting themselves each time in such a manner that the long axis of the body becomes parallel to the rays of light; and they swim away from the source of illumination as already explained. Frequently after reaching the extremity of the glass trough, many of the toads climb up its perpendicular wall. Attention has been drawn to this movement in connection with the responses out of water. The animals respond as if they are attempting to recede as far as possible from the source of stimulation. When the end of the dish, where the toads are congregated, is placed next to the light, they very promptly drop off the perpendicular glass wall into the water. Sometimes there is an attempt at orientation even before leaving the wall of the trough for the water. The results of the experiments in connection with both the jumping and swimming responses of young toads differ, decidedly, from the results of Parker's (I903, p. 29) suggestive work on Rana pipiens Schreber. He found that these animals were positively phototropic in light, from a Nernst lamp, even at 20,480 ca.m. Without regard to the side of the frog that was exposed to the light, they turned and jumped toward its source. The frogs oriented themselves until they faced the source of illumination 
and they remained in this position although the light was entirely unbearable to the human eye.

In connection with the responses of young toads both in and out of water, it would have been extremely interesting to have used a much longer experimentation trough in order to demonstrate whether or not the animals were seeking a certain optimum intensity of illumination. The writer planned to perform experiments of this nature if more material had been available: at the time, and he hopes to do so in the future.

In connection with these responses of young toads to intense light, it is of interest to recall the work of Pearse (I9Io) relative to frogs and toads. This writer (l.c., p. I 75) found that Rana clamata moved toward a light of 225 ca.m. from a six-glower Nernst lamp. Five specimens were subjected to the light. He also states (l.c., pp. I75-I76) that Rana sylvatica was exposed to photic stimuli from a light of the same intensity. His results are summed up in the following quotation (l.c.):

"This frog was more active than the last species, $[R$. clamata] and some individuals gave more decided phototropic reactions than did any member of the preceding species. There were, however, such differences in the reactions of the four animals used that they are tabulated separately. Individual No. 1 never failed to move straight toward the light. No. 2 was not as persistently positive after the eyes had been excised as before this operation, though it continued to give a majority of positive reactions. As individuals 3 and 4 were apparently indifferent to the light in their normal conditions, their eyes were not removed. The reactions of animals 1 and 2 were, however, strongly positive, and this condition remained even after the eyes had been excised; hence their skins served as photoreceptors as well as their eyes."

These results with frogs are quite different from the results of the writer with young toads. Such differences, however, are not at all surprising when it is recalled that not only are animals of different genera being considered, but also of different families; and further it must be kept in mind that on the one hand mature organisms are under observation and on the other very immature ones. Pearse (l.c,. p. I 76$)$ also experimented with Bufo americanus and Bufo fowleri. The records of the two species were not kept separate. The toads respond positively to a light of 225 ca.m., moving toward the source of illumination. Most of the animals used were adults, but a few were immature. None of them, however, were less than $2 \mathrm{~cm}$. long. It has been demonstrated that the present writer finds young toads to respond negatively to the light from a projection lantern. The 
difference in these results from those of Pearse is probably due to the fact that the writer employed more powerful stimuli in his experiments. Further, the writer used animals of much greater immaturity than was the case in Pearse's experiments.

\section{RESPONSE TO LESS INTENSE ARTIFICIAL LIGHT}

The young toads are next subjected to light of much lower intensity. The vessel containing the animals is placed directly in front of the bulb of an ordinary I 6 c.p. incandescent electric light. Within the field of experimentation the illumination is approximately $44 \mathrm{ca} . \mathrm{m}$. The first noticeable movement is the orienting response, all the toads so placing themselves, with respect to the light, that the longitudinal axes of their bodies become parallel with the longitudinal axis of the dish, which points directly toward the light. This response brings the toads into such a position that their heads are turned directly toward the source of illumination, and the median longitudinal axes of their bodies lie parallel with many of the rays passing through the bulb. However, with a light of this nature, it is incorrect to state, without qualification, that the median longitudinal axis of the body is parallel with the rays of light. Immediately after completing orientation, the toads jump in the direction of the light until they all reach the extremity of the vessel nearest to the source of illumination. The organisms remain oriented while traveling from one end of the glass trough to the other. Parker (l.c.) found that Rana pipiens Schreber oriented itself with its head toward the light and also moved toward the source of illumination. These were the responses to the intermediate light intensities between I and 20,480 ca.m. After the young toads had all reached the end of the vessel, it is turned around until the animals are moved to a position farthest from the source of light. They quickly perform the orienting response and again jump away toward the light. In this manner the animals are driven repeatedly from one end of the dish to the other. Usually, orientation is not performed so promptly nor do the toads jump so rapidly as in those experiments with the projection lantern. When the animals reach the end of the trough, they frequently climb up the end wall of the vessel as if to move still nearer to the source of illumination. There is no definite evidence that the median longitu- 
dinal axes of the toads lie parallel with all the rays of light, for the rays emerge from the bulb at various angles and many of them must cross within the area of experimentation.

These results seem to indicate that young toads respond positively to incandescent light of 16 c.p. They orient themselves in such a manner that the long axis of the body lies parallel to some of the incoming rays and the head is turned directly toward the source of light. They retain this orientation with considerable precision while traversing the entire length of the experimentation dish. The fact that the animals move as near as possible to the light, and in some cases climb to the top of the glass wall at the end of the vessel, leads one to infer that the intensity of the light is a factor in causing the movements, rather than the direction of the rays per se in the field. In connection with the experiments on young toads just described, it is interesting to compare the work of Parker (l.c.) on Rana pipiens Schreber. He noticed the interesting fact that,

"With the lower intensities the animals often did not react for from
five to ten minutes or even longer, and the jumping response was fre-
quently omitted; but their orientation was finally always with their
heads toward the source of light, that is, positive. In some instances
after a frog had remained ten minutes or more without changing its original
position, it was induced to jump by being touched from behind, and,
when this was done, the animal almost invariably turned first and then
jumped toward the source of light."

It has been demonstrated that stimuli from a r6 c.p. incandescent electric light affects young toads in much the same manner as Parker has observed with reference to frogs. The toads orient more slowly to the weaker light than to the stimuli from the projection lantern. Movement toward the incandescent light is also more deliberate than toward the light from the projection lantern.

Dickerson (I906, p. 66) also has noticed that toads respond positively to artificial light of relatively low intensity. Her statement is as follows:

"If we go to a pond at night, we shall have every opportunity both to see and hear toads, especially if we carry a lantern. Instead of being frightened by the light, they are attracted by it and may gather about it. If the lantern is set on the ground, they sometimes try to climb to its top."

The results of my experiments with less intense artificial light agree very largely with those of Cole (1907, p. 392) on Acris gryllus Le Conte. This observer states that the source of the 
photic stimuli was an electric light situated $50 \mathrm{~cm}$. above a flat surface on which the frogs were placed. A. gryllus faces the source of illumination and leaps toward it. When a frog jumps past the light, the animal remains with its back turned toward it for a short time. Then it turns in such a manner as to face the light and again leaps toward it. Cole (l.c., pp. 393-40I) also found that both A. gryllus and Rana clamata Daudin respond positively to light with an intensity of from I.25-5 ca.m. by turning toward the source of illumination, but that individuals of the latter species were much the slower in their responses. He noticed that the positive response of $A$. gryllus occurs more quickly and uniformly when light of $5^{-20}$ ca.m. is used. This is in accord with the present writer's experiments on Bufo americanus as it is also in accord with the results of Parker (1.c.) with Rana pipiens Schreber already mentioned. It should be stated that during these experiments of Cole with $A$. gryllus and $R$. clamata, the animals were confined in glass boxes which were of such dimensions that the amphibians could turn readily in any direction, but were unable to jump away. My experiments are also essentially in agreement with those of Mast (I9II, p. 2I9-220). This worker subjected seven toads to light from a single source. Two intensities were used, one of $\mathrm{I} 2.5 \mathrm{ca} . \mathrm{m}$. and the other of $25 \mathrm{ca} . \mathrm{m}$. Five of these toads were small ones, but the exact size is not given. The following quotation presents the results which have more direct bearing upon the experiments described in the present paper:

"They all oriented directly and fairly accurately. If placed on the table in the beam of light so that one side faced the glower they turned slowly but directly until they faced the light and then hopped or walked toward its source, stopping frequently for a few moments at intervals on the way. * * * The toads always went directly toward one or the other of the two sources."

\section{RESPONSE TO STRONG DIFFUSE DAYLIGHT}

It was found that young individuals of Bufo americanus respond to diffuse daylight of relatively strong intensity, and a number of experiments were performed in which light of this nature was employed. The glass trough containing the toads was placed on a table, having a black surface, at a distance of $50 \mathrm{~cm}$. from an east window. A glass plate, painted a dead black on the under side, was placed over the top of the experimentation dish. Then the strip of black paper, covering the 
end of the vessel facing the light, was removed. Such an arrangement modified, considerably, the effects of the cross rays.

It is noticed, after the dish containing the toads has been near the window for a few seconds, that the animals orient themselves with their heads toward the source of light and with the long axes of their bodies parallel with the longitudinal axis of the vessel used for the reaction work, but not parallel with the great majority of the rays, for these enter the dish at various angles notwithstanding the precautions already described. The toads jump away in a comparatively straight line toward the light. All the organisms are soon congregated at the end of the trough nearest to the window. Not infrequently some of them climb up the glass wall at the end of the dish and cling in that position. The vessel is turned around until the end where the toads are gathered is pointing directly away from the window. Those that are clinging to the glass side drop down to the floor of the trough. All the animals again turn their heads toward the window and move off, with the long axes of their bodies parallel with the longitudinal axis of the experimentation dish, in the direction of the source of illumination. In a short time they are all found at the extremity of the vessel. Experiments of this nature are continued for eight successive trials. Each time the animals move promptly from one end of the dish to the other. As in the experiments with incandescent electric light, there is evidence that orientation does not occur quite so promptly nor is locomotion so rapid as in the experiments with the projection lantern.

These experiments appear to indicate that young toads respond positively to diffuse daylight of somewhat strong intensity. They also exhibit definite orientation with the anterior end of the body turned directly toward the light. But it cannot be said that the long axis of the body lies parallel to the incoming rays, for it is evident after careful consideration that these must enter the experimentation trough at many and varied angles, numbers of them passing, more or less, along its entire length.

The responses of toads and frogs to strong diffuse daylight have been observed by other workers, and a brief comparison will be made with the results of some of their experiments. It is of interest to notice that, Graber (I884, p. I24) found that toads, Bufo vulgaris Laur, placed in a box with two compart- 
ments, one of which was darkened and the other exposed to diffuse daylight, moved toward the darkened compartment and tended to collect there. According to Graber's (l.c., pp. 39, 40) description of his own methods used in experimentation, the natural inference is that he used strong diffused daylight as a source of stimulation, except in those instances where it is stated specifically otherwise. The following quotation presents his results (l.c.):

"Da die meisten Versuche, die ich mit diesen ekelhaften Tieren anfieng, ein negatives Resultat ergaben, glaubte ich mich in eine genauere Lichtgefühl-Prüfung nicht einlassen zu sollen und geh' ich auch bei der Mitteilung der erhaltenen Reactionswerte ganz summarisch zu Werke.

"Aus der Vergleichung von Weiss und Schwarz geht zunächst hervor, dass, wie zu erwarten war, die dunkle Abteilung der hellen bei weitem vorgezogen wird.

$$
\text { “1) } \frac{\text { Weiss }}{\text { Schwarz }}=\frac{1}{8.4} \text {. }
$$

"Darnach ist also die Lichtscheu der Kröte (obiger Quotient beruht freilich nur auf 5 aber unter sich übereinstimmenden Beobachtungen) entschieden viel grösser wie jene des Frosches (aber kleiner wie die des Triton)."

While it is evident that the results of Graber's experiments differ from those of the writer, yet attention should be drawn to the fact, as indicated in the first paragraph quoted, that there was evidently some doubt in the author's mind as to the correctness of his own results. Plateau (I889, p. 82), however, working with Rana temporaria and Bufo calamata reached conclusions of an opposite nature. He demonstrated, when specimens were liberated in an experimentation box lighted by windows at one end only, that both specimens responded positively to the light and jumped toward the source of illumination. One infers from Plateau's (l.c., p. 8I) statement that strong diffuse daylight was used in his experimental work with amphibians. According to Loeb ( 1890, p. 90) frogs respond negatively to strong diffuse daylight. Torelle (I 903, p. 469) experimented with Rana virescens virescens and Rana clamata and demonstrated that both species oriented in such a manner that their heads pointed toward the source of illumination, diffuse daylight, and also that they moved toward the light. Dickerson (l.c., p. 32) states that the frog moves toward diffused light, probably meaning strong diffuse daylight. 


\section{RESPONSE TO WEAK DIFFUSE DAYLIGHT}

A number of experiments were performed with weak diffuse daylight. The light was obtained from a south window. The incoming rays passed through a small slit-like opening in the wall of the dark room before reaching the experimentation dish. The length of the opening corresponded with the width of the vessel and the width of the former was equal to the depth of the latter. The window through which the light entered was $4 \mathrm{~m}$. distant from the dark room (see Fig. I, A).

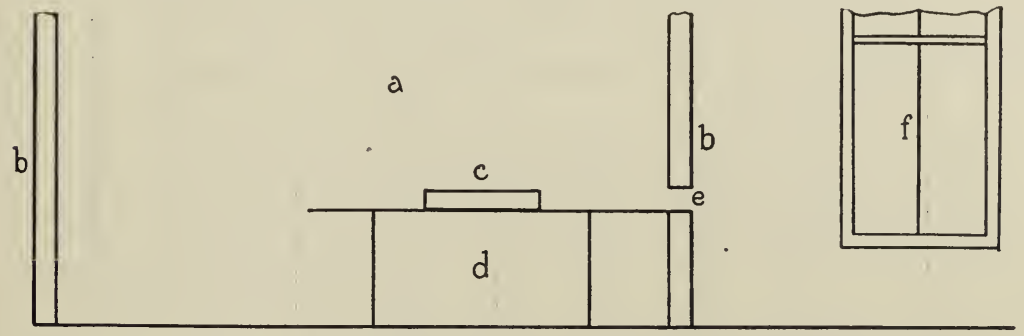

$A$

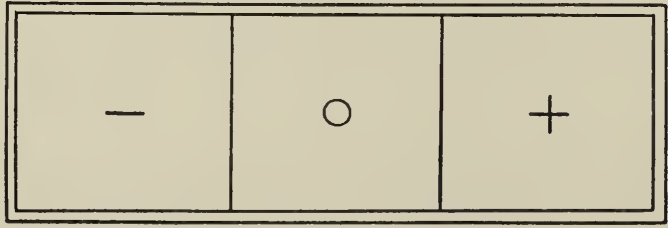

B

Figure 1. A. Sectional diagram showing plan of apparatus employed in testing responses of young toads to stimulation from weak diffuse daylight. B. Experimentation dish enlarged more than is shown in A. a, Interior of dark room; b, walls of dark room; c, experimentation dish containing young toads; d. table; e, opening through which light enters dark room; $f$, window through which light enters, situated in wall of outer room; +, positive; -, negative; 0, indifferent. (Not drawn to scale.)

The glass trough containing the toads was placed in close proximity to the slit-like opening. It was noticed that there was no immediate response to the light, neither by orientation nor by movement toward or away from the source of illumination. This being the case observations were taken every fifteen minutes, and the positions of the animals in the dish noted. The 
vessel was divided by transverse lines into three equal divisions (see Fig. I, B). Toads found in the section marked + were considered to respond positively to the light. Those gathered in the division marked - were enumerated as responding negatively. The organisms congregated in the space marked o were counted as being indifferent to the illumination. Table I indicates the results of six experiments with twelve individuals used in each experiment.

TABLE I

Responses of Young Toads to Weak Diffuse Daylight

\begin{tabular}{|c|c|c|c|}
\hline $\begin{array}{c}\text { Number of } \\
\text { Experiments }\end{array}$ & Positive & Indifferent & Negative \\
\hline 1 & 7 & 2 & 3 \\
2 & 6 & 1 & 5 \\
3 & 8 & 2 & 2 \\
4 & 6 & 2 & 4 \\
5 & 7 & 1 & 4 \\
6 & 8 & 2 & 2 \\
\hline Totals & 42 & 10 & 20 \\
\hline
\end{tabular}

The above table shows that out of a total of 72 responses, 42 of them may be considered as being positive, 20 as being negative, and Io as being indifferent. The writer performed many other experiments beside those indicated in Table I, some of which showed a rather higher percentage of positive responses than evidenced in the table; but it is believed that the results indicated there present a fairly representative series. From these results the inference is drawn that young toads respond positively to weak diffuse daylight. However, the orientation of the animals lacks the definiteness exhibited in the experiments with light of stronger intensities. Neither the motor response nor the orientation is so precise as is the case in the experiments with strong diffuse light. Many of the toads that collected in the section marked + faced the slit-like opening in the wall of the dark room through which the light entered. Those toads that faced the light have the median longitudinal axes of their bodies parallel with the longitudinal axis of the experimentation dish and also parallel with a portion of the incoming light rays. But it must be remembered that the rays cross at many and varied angles, and while it is true that 
many of these cross lights are cut out as the rays enter the dark room, yet it would be incorrect to state that all the rays of light are parallel with each other and with the median longitudinal axis of the bodies of the toads facing the light.

Graber (l.c., pp. I20, I2I) while making observations on Rana esculenta L., stimulated by means of weak diffuse daylight, "meist trüber Himmel," states results which lead to the inference that these animals react negatively to photic stimuli of such a nature. However, their responses were not so preponderantly negative as was the case of Bufo vulgaris Laur already mentioned. The following quotation will give an idea of his results (l.c., p. I2I):

\begin{abstract}
"Auch zeigt der Versuch, dass das Reactions-Verhältnis ein sehr constantes ist, indem die Weiss-Frequenz sich zwischen 11 und 18 und die des Schwarz zwischen 22 und 29 bewegt, und grössere Extreme, wie solche sonst sehr häufig sind, mit Ausnahme eines einzigen Falles ( $7: 33$ ) gar nicht vorkamen.
\end{abstract}

"Das Mittel-Verhältnis ist:

$$
\text { 1) } \frac{\text { Weiss }}{\text { Schwarz }}=\frac{1}{1.5} \text {." }
$$

Loeb (l.c., p. 89) experimented with frogs subjected to weak diffuse daylight, and found that they responded by moving away from the light.

\title{
VI. RESPONSE TO SUNLIGHT
}

No systematic experiments were undertaken in order to determine the effect of sunlight on the behavior of young toads. However, a few incidental observations were made and these were recorded.

The young toads were kept in a large glass aquarium jar when not under experimental observation. This chanced to be placed near a window with an eastern exposure. A narrow beam of sunlight entered the dish, and to one side of these rays of bright light was diffuse daylight. The animals jumped toward the side of the jar at which the sunlight entered. Usually they remained in the sunlight for some time. This response seemed to vary, for certain individuals remained in the direct light longer than others. However this may be, there was certainly a response to sunlight, evidenced by the toads jumping toward the window where the sunlight entered. Frequently the animals were found in the less illuminated portions of the jar, 
but they usually remained at the side of the vessel nearest to the window. On sunny days the writer often has observed that young toads respond both to moving shadows and moving objects. Sometimes they respond by crouching against the ground, and at other times by the jumping response. The response to moving objects has been noticed also on cloudy, days. The writer did not employ a heat screen during any of these observations. Therefore there was no definite attempt to isolate possible temperature responses from photic responses. However, he infers from the experiments of Pearse (l.c., pp. I 92-I95) that these responses are probably not due to temperature. My observations were recorded in the middle of the day, during the month of July. Similar responses occurring in the early spring or late fall may be due largely to temperature.

Torelle (I903, p. 469) working with Rana virescens virescens and Rana clamata noticed, in one series of experiments, that specimens of both species responded positively to sunlight, but that they did not stay in the circle of most intense illumination. Some individuals moved away without turning. Others turned and retreated some distance, and then oriented themselves with their heads pointing toward the incoming beam of sunlight. In another series of experiments in which specimens of the same species of frogs were placed in a box, admitting sunlight at one end and diffuse light at the other, Torelle (l.c., p. 47I) found that the animals "turned toward and moved to the end" where the sunlight entered. They did not stay within the area of strongest light, for they either moved to the opposite end of the box, or else backed, without turning, into the region where the light was less intense. These results correspond more or less to my observations on young toads; although unfortunately the present writer did not observe the kind of response when the animals moved into the less illuminated area. Dickerson (l.c., p. 7I) has noticed the response of young toads to sunlight. She states that, "They congregate in large numbers on sunny brown earth patches." Such places are near or among the grass. The observations of Miller (I909, pp. 659660) are in accord with those of Dickerson. The former has noticed that toads are rarely seen during the day unless it is cloudy. Late in the fall, however, they are found in the sunlight, among the grass. It should be stated that none of these 
writers, Torelle, Dickerson and Miller, indicate clearly whether the response is due to light or temperature.

\section{RESPONSE TO COLORED LIGHT}

A few experiments of a very general nature were performed with colored light as the source of stimulation. The young toads were subjected to the stimuli from a I 6 c.p. incandescent light. At first the light was passed through glass of various colors. Later the rays were transmitted through colored solutions prepared according to the directions recommended by Nagel (1898, pp. 649-655). Such light proved to be more nearly monochromatic, as was seen on examination with the spectroscope. The solutions were placed in a glass cell with parallel sides. Red and blue are the only colors that will be referred to here.

The young toads are seen to be scattered promiscuously throughout the experimentation dish when it is placed in the beam of light transmitted through the red solution. Frequently there is observed to be considerable hesitancy before the animals orient themselves with reference to the light. Some of them turn toward the light, while others exhibit no definite orientation. In some experiments it is observed that the number of toads responding positively to the light is slightly in excess of those responding negatively; but in other experiments the reverse proves to be the case, for the number of animals exhibiting the negative response to the light is somewhat greater than those exhibiting the positive response. Usually, however, it may be stated that a small majority of the toads turn in such a manner that their heads point toward the source of illumination. Some animals orient a few seconds after they are placed in the beam of light. Others wait much longer than this before they turn either away from or toward the red light. Certain individuals jump in the direction in which their heads are pointing, immediately after orientation is completed, while others wait from a few seconds to several minutes before they jump away. The jumping movement toward the red light is far less common than is the case with reference to the blue light. In general it may be said that the movements of young toads away from and toward the source of illumination are slower and with more and longer pauses between the jumps than is the case when 
white light is used. It is evident that red light is not a very effective form of stimulus, certainly the toads are not nearly so responsive to it as they are to white light.

In the experiments with blue light the toads are observed to be distributed at various different points in the experimentation dish. This is placed in the beam of light emerging from the blue solution. The animals turn with promptness toward the source of illumination. In most cases they jump immediately toward the light, or with a delay of but a few seconds. There are comparatively few pauses between the jumps and these are of short duration. Not only is the orienting response more prompt, but the movement toward the light is also more vigorous than is the case when the red solution is used. The orientation of the toads and their movement toward the source of illumination are very similar to the results observed with the I6 c.p. incandescent light when neither the red nor the blue solution is used.

Torelle (l.c., p. 478) found when single colored lights were used that specimens of Rana virescens virescens and Rana clamata always jumped in the direction of the blue light and remained with their heads pointed toward it, touching the glass. On a frog being placed close to the red light, it usually turned away from the source of illumination. In some cases the animal not only turned, but jumped away from the red light. When a frog was placed about $30 \mathrm{~cm}$. away from the red light, the animal generally remained there and did not jump toward the light. According to the experiments of Pearse (l.c., p. I89) with Rana palustris,

"The results show that the blue is apparently the most effective in the production of positively phototropic reactions, and that there is a regular graduation from blue to red, both in the percentage of positive reactions and in the rapidity with which the movements took place. * * * It is probable that these differences in the reactions are due to differences of the wave lengths, but they may be due to intensity differences."

These results of Pearse with $R$. palustris are largely in accord with those of the writer with young toads. Results similar to those of the writer on young toads when blue and red lights were used were obtained by Laurens (I9II, p. 267). He subjected Bufo americanus and Bufo fowleri to the stimuli from single monochromatic lights of equal intensity, using Nernst 
glowers for the source of illumination, and showed that members of both species reacted by giving motor responses, turning and jumping toward or away from the light. In one series of experiments with blue light, there were $25^{\mathrm{I}}$ positive responses and 37 negative ones. In another series of experiments with red light, there were 167 positive responses and $12 \mathrm{I}$ negative ones. The former series shows the percentage of responses to be 87 positive to 13 negative, while the latter series shows the percentage of responses to be 58 positive to 42 negative.

\begin{abstract}
"By way of summarizing the results of the experiments with single monochromatic lights in which both the eye and the skin acted as receptors, it may be stated that all four colored lights used produced positive responses. Blue light was the most effective, and the other lights formed a decreasing series, corresponding roughly to their relative position in the spectrum, the red light being but slightly more effective than darkness." (Laurens, l.c.)
\end{abstract}

This summary presents results which are in extremely clost agreement with those of Pearse (l.c.) on Rana palustris.

Some observations were recorded when stimuli from light of different colors, red and blue, were impinging upon the toads at the same time. The glass vessel containing the animals was so placed that the red light was situated at one extremity and the blue light at the other. The position was such that one end of the dish was in the beam of red light and the opposite end in the beam of blue light.

The young toads are placed in the center of the dish, approximately half way between the lights passing through the red and blue solutions. There is little more exhibited in the resulting responses than has already been recorded with reference to the single colored light. Orientation and movement toward the blue light are more definite and more vigorous, than they are with respect to the red light. By far the majority of the animals jump toward the blue light. A few individuals jump toward the red light. These make longer pauses. between the jumps than is the case of those toads moving toward the blue light. Frequently periods three minutes or more in duration elapse between some of the jumps. At times one or two specimens appear to be indifferent to either light. In several instances observations were recorded after a period of fifteen minutes from the time the toads were first placed in the experimentation dish. In these experiments twelve toads are used each 
time. Table II indicates the position of the toads with respect to the two colored lights for four sets of observations.

TABLE II

Responses of Young Toads to Colored Lights

\begin{tabular}{|c|c|c|c|}
\hline Experiment & Blue & Red & Indifferent \\
\hline 1 & 10 & 2 & 0 \\
2 & 7 & 3 & 2 \\
3 & 10 & 1 & 1 \\
4 & 9 & 2 & 1 \\
\hline Total No. of Responses & 36 & 8 & 4 \\
\hline
\end{tabular}

It is seen from the table that out of a total of 48 responses, 36 are toward the blue light, 8 are toward the red light, and 4 are indifferent, apparently being no response to either of the colored lights. The blue is evidently by far the more effective color with respect to the responses of young toads when stimuli from both red and blue light are impinging upon them.

The results recorded above are largely in accord with those of Graber (l.c., p. I25) on Bufo vulgaris Laur as indicated in the following quotation (l.c.):

"Dass auch bei diesen Reactionen wieder in erster Linie die Helligkeitsverhältnisse ausschlaggebend sind, geht schon aus dem Umstande hervor, dass einerseits Dunkel-Rot, andererseits Dunkel-Blau vorgezogen wird. Speciell aus der ersten Vergleichung, wo Rot sehr bedeutend dunkler als Blau und doch nur wenig stärker als letzteres besucht ist, könnte aber vielleicht geschlossen werden, dass diese Farbe als soloche der Kröte weniger angenehm als Blau sei.

$$
\text { 2) } \frac{\text { Rot }}{\text { Blau m. uv. }}=\frac{1}{1.2} \text { ?" }
$$

While it is true that in one series of experiments when "DunkelRot" and "Hell-Blau" lights were employed, the number of responses were 305 toward the former and 288 toward the latter, or in proportion of $\mathrm{I}: 0.9$, yet in another series when "Hell-Rot" and "Dunkel-Blau" were used, the responses were I08 to I42, or in the reaction-proportion of I : I.3. Graber (l.c., p. I22) experimenting with Rana esculenta L. obtained results somewhat at variance with those of the writer on young toads. The lights employed were "Hell-Rot" and "DunkelBlau." Three sets of experiments were performed, each con- 
sisting of ten trials. There were 736 responses toward the red and 464 toward the blue. The following quotation gives a brief statement regarding the experiments (1.c.):

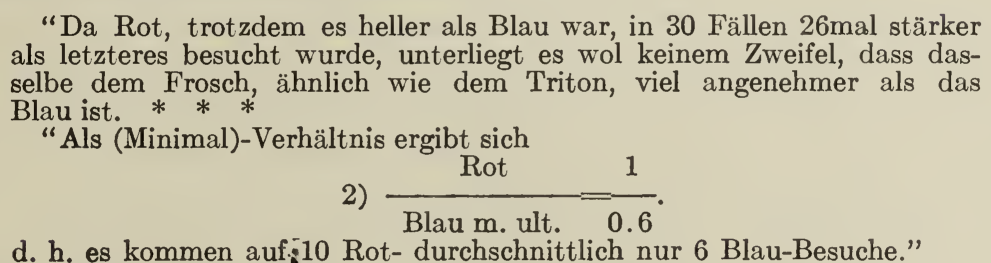

The results of Graber's experiments with Rana esculenta L., according to Torelle (l.c., p. 487),

"Can be explained only on the ground of a confusion arising as a result of using so many frogs (forty) at the same time in one receptacle."

As will be shown, Torelle (l.c., pp. 478, 479) obtained results with frogs, Rana virescens virescens and Rana clamata, exposed to the stimuli of red and blue lights both at the same time, much at variance with those of Graber (l.c.). For experimental purposes Torelle used a low, narrow box about $45 \mathrm{~cm}$. in length with a glass plate at each end. Red light was admitted at one end of the box and blue at the other. The frog was then submitted to the influence of the two lights. The response toward the blue light was immediate, the animal moving toward the source of illumination. Frequently the frog remained with its head against the glass and turned toward the light. Apparently there was no movement on the part of the frogs toward the red light. These results of Torelle's with frogs are largely in agreement with those of the writer with specimens of young Bufo americanus, as they are also with the statements of Holmes in regard to frogs. According to this author (I907, p. 349) the blue and the violet rays are the most effective in producing phototactic responses. When two lights are used, red and blue, frogs collect near the blue light.

The results of the writer with specimens of young Bufo americanus and those of Laurens (l.c., pp. 277-282) with Bufo americanus and Bufo fowleri are in accord. He worked with pairs of balanced colored lights and found that the toads reacted by giving motor responses, either jumping toward or away from the source of illumination. The animals also responded by 
orienting themselves so that their heads pointed toward or away from the light. In one series of experiments with red and blue lights, out of a total of 960 responses, 788 were toward the blue light, I 67 were toward the red light, and 5 were indifferent. Viewing the responses from the percentage basis, 82 per cent were in favor of the blue light, while only i 7 per cent were in favor of the red light. It will be noticed that the results in the main are similar to those obtained with single monochromatic lights. However, it should be stated that the responses were not quite so quick as was the case with single lights. There were movements toward both lights, but those toward the blue far outnumbered those toward the red.

"It cannot be said that there is much evidence in favor of positive phototropism for the red light." (Laurens, l.c., p. 280.)

In comparing these experiments of Laurens, with balanced blue and red lights, with those of Pearse (l.c.) on Rana palustris with single blue and red lights, it is of interest to observe that the results in the two cases very largely agree, in that there is a greater number of positive responses toward the blue light than there is toward the red light. However, it should be noticed that there is a much larger percentage of positive responses with reference to the blue light in the former's experiments with balanced blue and red lights, than is found to be the case in Pearse's experiments with blue and red lights used singly. It should also be noticed that in Pearse's experiments the results indicate many responses that were indifferent with respect to the red light.

\section{RESPONSE TO CONTACT}

Some observations were made on young specimens of Bufo americanus with reference to their responses to contact stimuli. While no systematic experiments were undertaken in order to study the effect of contact on the behavior of the animals, yet certain incidental observations were recorded. Some data were obtained regarding the influence of contact stimuli on the response to light. Record was made of observations on a form of a contact response resembling the death-feint among Arthropods. Some description also was given of the work of other writers with regard to the contact responses of toads and frogs.

During the experiments with light there were usually a num- 
ber of young toads in the experimentation dish at the same time. Occasionally in jumping toward or away from the source of illumination two individuals come in contact with each other. Frequently this contact appears to have no effect upon the animals so far as their response to light is concerned. At other times one or both of the toads pause for a few seconds before again reacting with the motor response with reference to the light. Generally, however, when contact occurs it seems to act as a stimulus in inducing the motor response. This is noticeable when a toad, in jumping, comes in contact with a stationary individual, the latter's motor response being invoked. If a toad does not respond to the light for a few seconds, but remains quietly resting in one position, and if then it is stimulated by means of another animal jumping against it, the motor response may result and this may be followed by the animal responding to the photic stimuli. These statements apply more largely to the experiments with the weaker intensities. Parker (l.c., pp. 28,29 ) found when subjecting frogs, Rana pipiens Schreber, to the lower light intensities from a Nernst glower that,
"In some instances after a frog had remained ten minutes or more without changing its original position, it was induced to jump by being touched from behind, and, when this was done, the animal almost invari- ably turned first and then jumped toward the source of light."

Pearse (l.c., pp. I77, I78) in discussing "the influence of mechanical stimulation on the photic reactions of the toad," Bufo americamus and Bufo fowleri, when subjected to a light intensity of 220 ca.m. states that,

"In jumping about they stimulated each other in a mechanical way. $* * *$ It is evident * * * that mechanical stimulation exerts an influence on the phototropism of the toad by enforcing the effect of light, or, it could perhaps better be said, that the mechanical stimulation furnishes the impulse to locomotion, while the light is effective in determining the direction of the movement after locomotion has been established."

The writer has noticed in his experiments with the less intense illuminations that when several young toads move into the angles formed by the bottom and sides of the experimentation dish that the contact of their bodies and of the solid surfaces of the vessel seem to inhibit the motor response for some time. The animals remain quietly resting with their bodies in rather close contact. During the experiments with weak diffuse daylight, it was found that when stones were placed about $25 \mathrm{~mm}$. apart 
in the experimentation dish that there was a tendency for some of the toads to move into the spaces between the stones. The writer has frequently observed a similar "habit" on the part of mature and partially mature frogs. Large numbers of frogs, chiefly Rana pipiens Schreber, were kept in two large tanks in a basement room, the tanks being in diffuse daylight. It was a very common sight to find as many as thirty individuals crowded closely together in the angles formed by the sides and bottom of each tank. Frequently they were congregated in the more shaded corners, and the taking of such positions might be due in part to a response to light. However, they were sometimes observed to be gathered in corners that were not so shaded. At other times frogs were found to be grouped in the corners of the tanks, both in shaded and unshaded situations. Not infrequently frogs were observed to be distributed sparsely about the more central and open portions of the tanks. Such groupings as have been described are in all probability due to responses to contact stimuli. The movement into the shade may be due in part to vision as Torelle (l.c., p. 470) has suggested.

Other writers have recorded observations on the contact responses of toads and frogs. Torelle (l.c., p. 477) experimented with specimens of Rana virescens virescens and Rana clamata in a jar of water and found that the propensity of the frogs to place themselves in contact with solid bodies "is apparently stronger when the temperature is lowered." The following interesting facts are quoted from the author's work cited above:

\footnotetext{
"When a rock was lowered into the jar in such a way that a small space was formed between it and the wall of the jar, the frog crawled into this space and remained there. When a space was formed between the bottom of the jar and the rock, it crawled into that. This was tested several times, and was also observed when the temperature of the water in the aquarium in which the frogs were kept was lowered $10^{\circ} \mathrm{C}$. and below. When this was done, all the frogs responded, either by flattening their bodies against the stone floor, or by creeping under the rocks usually kept there. It therefore seems that the frog is stereotropic in temperatures between $10^{\circ} \mathrm{C}$. and $4^{\circ} \mathrm{C} . "$
}

These experiments of Torelle's, considered with those (l.c., p. 476 ) on frogs out of water, seem to bear an interesting relation to hibernation. It is probably true that this instinct is not due to a single but to several causes. The increase of stereotropism with a lowering of the temperature is an important physiological change which may be related to the burrowing 
response of hibernating frogs. Dickerson (l.c., p. 7I) has observed the tendency of young toads, Bufo americamus Le Conte, to crawl "under stones and chips, in the cracks of boardwalks or under the protecting cover of leaves and grasses." The young toads to which she referred had left the water just recently and were therefore very delicate creatures, and they remained during the daytime in such protected situations as have been mentioned. So that while these responses are probably due in part to contact stimuli, yet other stimuli also such as light and temperature undoubtedly have considerable influence in bringing them about. The burrowing response of young spadefoot toads, Scaphiopus holbrookii Harlan, exhibits itself early in the life of the individual (Dickerson, l.c., p. 56), and is in part at least a response to contact. According to Holmes (l.c., p. 35 I) there is a tendency for frogs and toads to crawl under stones and to place themselves between objects. In such positions they remain quiet. This propensity to move into such situations is more pronounced in the case of toads. $\mathrm{He}$ considers such responses to be of a thigmotactic nature, although from his discussion it may be inferred that at times light also plays some rôle.

Considerable care was used in handling the young toads during the experiments with light. They were removed from the aquarium jar and placed in the experimentation trough by hand. In order that such contact should modify the response to light as little as possible, the toads were left undisturbed for approximately fifteen minutes before being subjected to the photic stimuli of the experiment. Should the toads while being transferred from one vessel to another be handled with undue pressure and roughness, they sometimes assume an immobile state. As this response was a somewhat unfamiliar one to the writer a number of observations were recorded concerning it.

Frequently when young specimens of Bufo americanus are handled, the contact stimulus causes them to become motionless; they react with the death-feigning response. Certainly they assume an attitude which is comparable to that assumed by many Arthropods when they are said to feign death. The legs are drawn up closely against the body and they assume a more or less rigid condition, the animal remaining motionless. Sometimes a toad lies so absolutely quiet that even the respiratory 
movements are unobserved, and the eyes may be closed. The attitude assumed by the death-feigning animal is not always as just described. Instead of the legs being drawn up in close contact with the body they may be somewhat extended. A young toad may be made to feign death by being placed on its back in the hand or on the laboratory table, and held in that position for a few se:conds. There is considerable variation among different individuals regarding the length of time of the death-feigning response. Some feign death for a few seconds only, while others retain the death-feigning posture for a minute, and occasionally even for a longer time. When young toads are exposed to the beam of light from the projection lantern during the death-feint, the length of the response seems to be somewhat shorter, than when the animals are induced to feign death in weak diffuse daylight. Here again there is much variation, for in some instances it appears to make no difference to the toad as to the intensity of the light to which it is subjected. If the animal is put into the death feint in diffuse daylight and is then exposed to the bright beam of light from the projection lantern, the length of the response is curtailed, in fact the toad at times arouses immediately from the death-feint. A young toad generally arouses from the death-feint rather suddenly. If the animal is on its back, first one leg and then another is extended until the legs are no longer pressed closely against the body. If the eyes are closed while in the death-feint, they are opened sometime during the process of arousing from the response, while the legs are being extended. Immediately after the eyes have been opened and the legs extended, the toad turns over with the ventral side down. While it is true that the young toad usually arouses from the death-feint rather abruptly, there are individual variations, some animals being more deliberate in the process than is the case with others. Young toads may be promptly aroused from the death-feint by sudden tactual stimuli, as for example, a touch on the body, though this may at times cause a continuance of the response, or by dropping them into a jar of water. Dickerson (l.c., pp. $7 \mathrm{I}-72$ ) has observed the death-feigning response in young toads, as indicated by the following quotation:

"When they are handled they play dead for seconds at a time and finally 'come to life' sticking up their little orange paws in most ridiculous fashion before they tumble over and hop away." 
Mature specimens of Bufo americanus will also feign death. The writer has frequently caused toads to exhibit this response by placing them with the back down and in close contact with some solid surface, meanwhile holding them firmly in that position for approximately thirty seconds more or less. They sometimes respond to stimuli of this nature by feigning death for one or more minutes. Near Ann Arbor, Michigan, the leopard frog, Rana pipiens Schreber, is very common. Mature specimens taken in that locality frequently have been made to exhibit the death-feigning response by rough handling and by placing them on their backs on the laboratory table and holding them securely for some time in such a position. Mature toads and frogs exhibit much individual variation in reacting with the death-feigning response. The response is elicited in some animals much more readily than in others. In some instances it seems to be practically impossible to induce the response. The length of the death-feint also varies considerably in different individuals. The death-feigning response is undoubtedly of the same nature as that which Verworn (I898) ${ }^{3}$ calls hypnosis. According to this writer specimens of Rana esculenta when turned on their backs, become motionless. Sometimes the hind legs are drawn close to the body, and the eyes are closed. While the animals lie in this position, their muscles are in a condition of "tonic contraction." Hypnotized frogs may assume peculiar attitudes, as if in attempting to right themselves the movements were suddenly inhibited. Verworn (I899, pp. 358-359) in discussing the hypnotic state of frogs makes the following statement:

\footnotetext{
"The phenomena of prolonged reflex tone after brief stimulation may be seen still more clearly in frogs that have been deprived of their cerebrum. If such a frog sitting quietly in the customary squatting attitude be gently stroked by two fingers along the sides of the spinal column, he raises himself upon his extremities by contracting their muscles, and stands, sometimes more than an hour, in this grotesque position."
}

According to Verworn (l.c., p. 496) if a frog is seized suddenly and held with a firm grip, and is then placed with its back down the animal remains immobile. A very peculiar contact response on the part of certain toads, Bombinator igneus and Bombinator

${ }^{3}$ Beiträge zur Physiologie des Centralnervensystems I. Die sogenannte Hypnose der Thieren. Jena, 1898, pp. iv +92 . This paper was not accessible, but some discussion of it is given in the section on "Hypnotism," Holmes (1907, pp. $59,60,61)$, and in a review by Gotch (1898). 
pachypus, appears to be somewhat akin to the death-feint, or to the hypnotic state already described. The following quotation taken from Gadow ( I go I, p. I 56) gives a good description of the posture assumed by these toads during the response:

"When these toads are surprised on land, or roughly touched, they assume a most peculiar attitude. $* * *$ The head is partly thrown back, the limbs are turned upwards with their under surfaces outwards, and the whole body is curved up. *** The creature remains in this strained position until all danger seems passed."

The following interesting description of the death-feigning instinct among toads and frogs is given by Dickerson (l.c., p. 34):

"Many of the Salientia play dead in response to an unexpected tactual stimulus. The common toad will often hold the legs tight against the body and inhibit all movement - even the breathing vibrations of the throat-when seized by a dog or other enemy. The leopard frog may stretch the legs backwards stiff and straight, fold the arms on the breast, and inhibit the breathing movements. It certainly looks like a dead frog as it lies motionless in one's hand for fully a minute; suddenly, with a lightning movement, it is gone before the hand can be closed over it. The cricket frog plays dead in water. Taking a position with arms and legs rigid and throat collapsed, it floats about helplessly like any stick or leaf."

Dickerson (l.c., 87-88) considers the death-feigning response of the toad to be a protection to the animal. She states that,

"The toad is fitted for his place in life by what he does, as well as by what he is. Let an enemy seize him roughly, and he is a dead toad. 'Playing dead' saves him many a time. He will lie on his back with scarcely any perceptible motion for minutes at a time. Even the breathing movements seem to be suspended. Suddenly one leg is thrust out, then another, the eyes open wide, and in an instant more, the toad has turned over and is ready for new emergencies. Whether this habit is a protective instinct, or whether the toad really is insensible from fright during the time that it 'plays dead,' the resulting protection is the same, for, as a rule, animals that feed upon living food associate motion with life so firmly that they pay no attention to a motionless creature."

Facts similar to those described by Dickerson have been observed by Holmes (l.c., pp. 59, 60, 6r), who considers this immobile condition of the frog to be an hypnotic state. According to this author the position assumed varies at different times. Some individuals are more easily hypnotized than others, and the duration of the hypnotic state also varies in different frogs. Sometimes a frog will remain immobile for hours. A frog may be aroused from its condition of hypnosis by some sudden stimulus, and the awakening often occurs immediately.

Sometimes when removing the young toads from the aquarium jar to the experimentation dish, the writer observed that the 
animals respond to contact in another manner than that of the death-feint. The body of the toad is spread out and closely pressed against the bottom of the aquarium, and the lungs are filled with air until the animal becomes as wide as it is long. The head is also bent downward and placed on the bottom of the aquarium. As long as the animal retains this position it remains motionless. Reactions similar to these may occur as responses to a moving shadow or object, as for example the writer's hand when it is reached into the aquarium to remove the young toads. So that these are responses to both tactual and visual stimuli. Dickerson (l.c., pp. 33-34, 86) also has drawn attention to this form of response in the toad. According to Holmes (l.c., p. 32),

"Frogs sometimes swell the body before being seized as if in anticipation of their capture, and they are especially apt to do this after being lightly touched. Touch a frog that is resting quietly, and if the creature does not hop away, one may see the body puff up; and if the body is touched two or three times, the swelling will continue until the lungs contain their maximum amount of air. *** Frogs often avoid capture better by remaining perfectly quiet than by attempting to get away by jumping. * * * Safety is also sought occasionally by crouching close to the ground, and more often by crawling under some object that promises to afford shelter."

Another interesting response to contact stimuli is the "singing" or croaking of frogs and toads. The croaking of frogs and toads is readily induced by stroking the body, especially on the back or sides. They also will croak when kept in an aquarium. The contact of one animal against another is often sufficient stimulus to produce this sound. It is not improbable that light as well as contact may play some, rôle in connection with the croaking reflex. The writer frequently has observed hundreds of toads in bright patches of moonlight along the shores of ponds and marshes. On such occasions their heads are raised, and the throat-sac is puffed out to a large size, owing to their vigorous "singing." At such times they give little "attention" to the observer, and one may pick up a toad, placing it upon the palm of the hand where it will continue to "sing" with astonishing vigor.

\section{DISCUSSION}

It has been pointed out, in the experiments with the projection lantern, that young specimens of Bufo americanus orient in such a manner with reference to the light that the head points 
away from the source of illumination. After orientation is completed the animals retain the position assumed with reference to the light, the medium longitudinal axis of the body being kept practically parallel with the incoming rays. So far as the writer's observations are concerned, there is no definite evidence that young toads orient to light according to the method of "selection of random movements," as advocated by.Holmes (I 905) (though the present writer believes that it may function in some modified form), or by that of "trial" so ably propounded by Jennings (I 904) and (I 906), also discussed by Mast (l.c.,), and many other writers. Usually the young toads orient promptly and definitely. If the head is pointing toward the light, they make a turn of $180^{\circ}$ so that the anterior end of the body is pointed directly away from the source of illumination. Should the toad be in such a position that the median longitudinal axis of the body lies at right angles to the rays and facing the light, the animal makes a turn of $90^{\circ}$, thus bringing the head into such a position that it points directly away from the source of illumination. There are no preliminary movements, either "trial" or "random" ones, during or immediately preceding the orienting response, so far as the writer observed. But as Mast (l.c., p. 2 I 4) has suggested, these facts do not preclude the possibility of preliminary movements when other forms of stimuli impinge upon the toads. After orientation is completed the young toads jump away from the source of illumination along a comparatively straight path, the medium longitudinal axis of the body being parallel with the rays of light. During such motor responses the direction of the rays in the field may be a guiding factor. It is not impossible that they may be both a guiding and a correcting factor, if we should apply the theory advocated by Holmes (l.c., pp. Io8-Io9). While there is little evidence of such responses on the part of young toads, nevertheless the applicability of Holmes's modified "trial and error method" with reference to the responses of animals which orient themselves "according to the usual scheme" is worthy of careful consideration. The present writer believes that it is absolutely futile to attempt to explain the responses of all animals by any one theory, or from any one point of view.

Such a response on the part of young toads as has been described by the writer is a tropic response in so far as it fits, 
the definition of Jennings (I909, p. 307), however, the writer does not wish to be understood as believing that internal factors, changes in bodily states, play no rôle in the orientation of young toads to light. This matter was not discussed in connection with the responses to intense artificial light, largely because the wr ter was attempting to record the responses as they occurred in the majority of cases. There are occasional examples when it is observed that one toad orients to the light much more slowly and hesitatingly than another. Some toads jump away from the light more rapidly than others and along a straighter path. There also is found to be variations in such responses on the part of the same animal on different occasions. These facts seem to indicate modifications in the bodily conditions of the animals concerned, especially when it is remembered that both the environment and the kind of stimuli remain unchanged. Loeb (l.c., p. 24) and (I9I2, p. 47) early recognized the importance of differences in the physiological conditions of animals as modifying factors in animal responses. This subject has been discussed by the present writer (I9I2, pp. $28 \mathrm{I}-283$ ). It is not improbable, in the writer's experiments with young toads, that before orientation the animals are, as it were, in a condition of unstable equilibrium with reference to the light, and that the orienting response is one of adjustment; and further, after orientation is completed the toads are then in a condition of relative stability toward the light, so far as orientation is concerned, and they exhibit further response by jumping away from the source of illumination. With reference to orientation in general, may it not be a fact that previous to the orienting response the bodily state of the animal differs from its condition after orientation is complete?

The responses of young toads to the light from the projection lantern seem to indicate that the unequal light intensity on the two sides of the body is a factor in inducing the animals to orient so promptly and definitely. According to Holmes (1907, p. 346), frogs orient with respect to light in general in much the same manner. Pearse (l.c., pp. I 72-205) apparently takes a similar point of view with reference to the orientation of specimens (some of them immature) of Bufo americamus and Bufo fowleri to light of 220 ca.m. intensity (see particularly l.c., pp. 204-205). The orientation of specimens of B. ameri- 
canus (some of them immature), as described by Mast (l.c., pp. 2I 4-2I 5, 2I 9-220) appears to occur much in the same way as observed by the writer in young toads. The intensities of the lights employed by Mast in his experiments were 12.5 and 25 ca.m. It is probable, during the orienting response of young toads, that the light acts in some such manner as described by Loeb (1905, p. 32), and to which Mast (l.c., p. 223) practically assents. Even so, though the light should act "at a constant intensity," such a fact does not necessarily preclude the influence of the differences in intensity on the two sides of the animal's body, during orientation.

In regard to the effect of light intensity upon the orientation of young toads, mention should be made of Mast's (l.c., pp. 2 I 9-220) extremely interesting experiments with specimens of Bufo americanus, some being immature. Two lights of different intensities were employed, one being I 2.5 ca.m. and the other 25 ca.m., and the source of illumination was two Nernst glowers, the two beams of light crossing at right angles. When a toad was placed, with one side turned toward the glower, in the beam of light of lesser intensity, it oriented directly and accurately, and then jumped toward the source of illumination. However, when the animal reached the intersecting beam from the light of greater intensity, instead of orienting toward this light, it continued to jump toward the weaker light. Altogether 42 trials were made, 36 of these being as described. In 6 cases only did the toad turn toward the stronger light when it reached the point of intersection of the two beams, and these six trials were all with the same individual. Seven toads only were used in the experiments. It would seem in a series of experiments exhibiting results of this nature that the effect of light intensity was modified as an orienting factor, or why did not the animals orient toward the light of stronger intensity. The present writer offers two suggestions which may prove to be partially, if not fully explanatory of this. First, the eyes are strongly stimulated by the light from in front, and the response to such stimulation in itself may result in producing an inhibitory effect upon the toad in so far as its response to the stimuli from the intersecting light is concerned. While it is true that in toads both skin and eyes are photoreceptors as Pearse (l.c.) has proved, it is evident that the cross rays from the stronger light 
would reach one eye only with full effectiveness. Second, if animals with image-forming eyes go toward a source of light, because they perceive the light itself and follow it "much as an animal pursues any other object of interest" as indicated by Graber (l.c., p. 248), Torelle (l.c., p. 47 I), Holmes (I 905a, pp. 34I, 344-345) and (I 908, p. 496), and Mast (l.c., pp. 2 I 9, 223), then such behavior may present a partial explanation as to the reason why the toads used in Mast's experiments did not go toward the stronger light, for the "attention " of the animals may have been so fully occupied with the light in front of them that they did not turn into the intersecting beam, and jump toward the source of the stronger light. Further, it must be recalled, as Mast (l.c., p. 223) himself has suggested, that the direction of the rays in the field may be a guidance to the toads, especially if they go toward an object because they see it. Then, the after effects of the directive weaker light may have been sufficient to keep the toads moving along the path already taken, even when they reached the strong intersecting beam of light. In so far as this work of Mast's applies to the writer's experiments with young toads, certain facts should be kept clearly in mind regarding the latter's experiments, that the animals employed were extremely immature, that light approximating ro, ,oo ca.m. intensity was used, and that the toads reacted negatively to the photic stimuli. From what is known of the habits of toads, it was to be expected that the animals would respond negatively to the strong stimuli from the projection lantern. Toads are very largely nocturnal animals, and are more commonly seen about twilight when they leave their places of "concealment," which they have occupied during the daytime.

The young toads respond positively to all the lesser light intensities of white light. In these experiments it seems as if the difference in the intensity of the stimuli on the two sides of the body was an important factor in orientation. This subject has been discussed in connection with the responses to the light from the projection lantern, and therefore will not be dwelt upon here. In jumping toward the light it is hardly probable that the rays per se in the field are a very important element in guiding the toads, for it has been stated that there must be many cross lights in the field of experimentation. Of course there is a certain part of Holmes's theory (1905, pp. Io8- 
I09) that might apply here as a partial explanation, for a portion of the rays are parallel with each other and with the median longitudinal axes of the bodies of the toads. In the experiments in the dark room the principal object in the toad's field of vision is the light, and it is probable that the animals jump toward it because they see it, an idea that has been mentioned before. The light also may act continuously as Mast (l.c.) has suggested, and somewhat as Loeb (I 890, p. 90) stated more than twenty years ago with reference to frogs when diffuse daylight was used as a stimulus. The following quotation gives Loeb's point of view :

\footnotetext{
"Dass auch beim Frosch das Licht als konstante Reizursache wirkt, geht daraus hervor, dass die Thiere dauernd an dem der Lichtquelle entgegengesetzten Ende des Kastens sitzen bleiben."
}

In experiments with weak diffuse daylight, orientation is not a prominent feature in behavior, but there is some evidence of a tendency for the toads to gather toward the source of illumination.

Many of the responses of young toads to contact stimuli are probably adaptive ones, such as creeping under and between objects. Even so peculiar a response as that of the death-feint may be of such a nature, as the observations of some writers seem to indicate. It is true that in the case of some of the Arthropods, it is rather more difficult to see how the deathfeigning response serves any adaptive purpose. The act of crouching against the ground and of inflating the lungs with air may be another example of a protective device. It would be of considerable scientific interest, for some investigator to make a long and varied series of observations with reference to the contact responses of young toads, and see in how many instances such responses were adaptive in function.

\section{SUMMARY}

Specimens of Bufo americanus Le Conte, approximately i $4 \mathrm{~mm}$. in length were collected near Ann Arbor, Michigan. They respond negatively to the light from a projection lantern, with an approximate illumination of 10,000 ca.m. within the field of experimentation. The animals jump away from the light toward the opposite end of the dish. If they are left in that 
situation for some time, some of them climb up the perpendicular glass wall at the end of the vessel. This places them out of the most intense glare of the light. The young toads orient promptly and definitely, by turning away from the source of illumination and so place themselves that the longitudinal axes of their bodies lie parallel with the incoming rays. This position in relation to the rays of light is maintained while traveling from one end of the dish to the other, and the pauses between the jumps are brief, so that the animals move with a fair degree of speed. The responses in water are similar to those already described, the toads swimming away from the light.

The young toads respond positively to the light from a I6 c.p. incandescent light, with an illumination approximately of 44 ca.m. They also respond in a similar manner to strong diffuse daylight, to weak diffuse daylight, and to sunlight. Except in the case of diffuse daylight, the animals jump toward the source of illumination in a comparatively straight path. It cannot be said that the median longitudinal axes of the bodies of the toads are parallel with all the incoming rays, because many of the rays enter the experimentation dish at various angles and there must be cross lights within the field of experimentation. While the animals jump toward the light with considerable promptness, their motor responses are perhaps not so quick as in the experiments with the projection lantern. At times it seems as if the toads do not travel in quite so straight a path as is the case when the intense artificial light is used as a source of stimulation. The toads orient fairly definitely and accurately, but not so promptly as when the projection lantern is employed. At times, when responding to sunlight, the animals come to rest in diffuse daylight, if it is nearby. Neither the movement toward the light nor the orientation is so definite as in the case of the stronger intensities.

It is not improbable that both light intensity and ray direction in the field are factors in these photic responses. During orientation light intensity may play the more important rôle, while the rays in the field may act as a guiding factor after orientation is complete, though this does not necessarily do away with the effect of intensity. In the positive responses vision is an element not to be ignored, and it is probable that 
the light acts continuously. Further, it is not impossible that a modified form of "trial and error" may function as the animals travel toward or away from the source of illumination. In the experiments with weak diffuse daylight, ray direction in the field probably exerts comparatively little influence upon young toads.

Young toads react to light passed through red and blue solutions by giving motor responses. When red light is employed singly, it is noticed that the stimuli are not very effective. There is a tendency for the animals to act negatively, both by turning and jumping away from the light. The responses are less definite than when either white or blue light is used. When blue light is employed the toads both turn and jump toward the light, and they do so with more promptness, than is the case when red light is used. When red and blue lights are used at the same time, more animals jump toward the blue light than they do toward the red light. Some toads jump toward the red light, and a few individuals appear to be indifferent.

Young toads subjected to light react to contact stimuli by giving the motor response. If a stationary individual is stimulated by another animal jumping against it, the former responds either by turning or by jumping away. Frequently after such a motor response, the animal follows it up by reacting to the light. In the experiments with the lesser light intensities, the young toads may respond to contact by several of them gathering in the angles formed by the bottom and sides of the experimentation dish. They remain in such situations with their bodies in close contact.

Young toads frequently react with the death-feigning response when handled with undue pressure and roughness. During such response they remain immobile, with their legs drawn up against the body. A toad may be caused to respond in this manner by placing the animal on its back and holding it in that posture for a few seconds. The length of the deathfeint varies in different individuals. If a toad has been made to feign death in diffuse daylight, the response may be curtailed by suddenly flashing a beam of light from the projection lantern upon the animal. Young toads usually arouse from the death-feint abruptly. A sudden tactual stimulus will effect this. The death-feigning response may probably result in producing 
a bodily condition in young toads not far removed from that of hypnosis described by Verworn in other animals.

Young toads will also respond to contact in another manner. Sometimes when touched the body is pressed closely against the ground, and the lungs are inflated with air, the head also being bent downward. While in this position an animal remains motionless. It is likely that many of these responses to contact on the part of young toads are adaptive in function.

\section{BIBLIOGRAPHY}

Cole, L. J. An Experimental Study of the Image-Forming Powers of Various 1907. Types of Eyes. Proc. Amer. Acad. Arts and Sci., Vol. XLII, No. 16, pp. 335-417.

Dickerson, M. C. The Frog Book. New York, xvii +253 pp. 1906.

Gadow, H. Amphibia and Reptiles. Cambridge Natural History, Londen and 1901. New York, Vol. VIII, xiii +668 pp.

Gотсн, F. The Hypnotising of Animals. Nat. Sci., Vol. XIII, No. 82, pp. 417 1898. 419. (Review of Beiträge zur Physiologie des Centralnervensystems I. Die sogenannte Hypnose der Thieren. By Max Verworn.

Garber, V. Grundlinien zur Erforschung des Helligkeits- und Farbensinnes der 1884. Tiere. Prag und Leipzig, viii $+322 \mathrm{pp}$.

Holmes, S. J. The Selection of Random Movements as a Factor in Phototaxis. 1905. Jour. Comp. Neurol. and Psychol., Vol. XV, No. 2, pp. 98-112.

1905a. The Reactions of Ranatra to Light. Ibid., Vol. XV, No. 4, pp. 305349.

1907. The Biology of the Frog. 2d ed. New York and London, ix $+370 \mathrm{pp}$.

1908. Phototaxis in Fiddler Crabs and its Relation to Theories of Orientatation. Jour. Comp. Neurol. and Psychol., Vol. XVIII, No. 5, pp. 493-497.

Jennings, H. S. Contributions to the Study of the Behavior of Lower Organ1904. isms. Carnegie Inst. of Washington, Pub. No. 16, Washington, $256 \mathrm{pp}$.

1906. Behavior of the Lower Organisms. New York, xiv $+366 \mathrm{pp}$.

1909. Tropisms. Rapport au VIme Congrès International de Psychologie, Genève, pp. 307-324.

Laurens, H. The Reactions of Amphibians to Monochromatic Lights of Equal 1911. Intensity. Bull. Mus. Comp. Zoöl., Harvard College, Vol. XLIII No. 5, pp. 251-302.

Lовв, J, Der Heliotropismus der Thiere seine Uebereinstimmung mit dem 1890. Heliotropismus der Plfanzen. Würzburg, $188 \mathrm{pp}$.

1905. Studies in General Physiology. Chicago, Part I, XIII + 423 pp.

1912. Mechanistic Conception of Life. Chicago, $232 \mathrm{pp}$.

Mast, S. O. Light and the Behavior of Organisms. New York and London, xi + 1911. $410 \mathrm{pp}$.

Mrller, N. The American Toad (Bufo Lentiginosus Americanus, Le Conte). 1909. Amer. Nat., Vol. XLIII, Nos. 515, 516, pp. 641-745.

Nagel, W. A. Ueber flüssige Strahlenfilter. Biol. Cent., Bd. XVIII, Nr. 17, 1898. pp. 649-655.

PArker, G. H. The Skin and the Eyes as Receptive Organs in the Reactions 1903. of Frogs to Light. Amer. Jour. Physiol., Vol. X, No. 1, pp. 28-36.

Pearse, A. S. The Reactions of Amphibians to Light. Proc. Amer. Acad. Arts 1910. and Sci., Vol. XLV, No. 6, pp. 161-208. 
Plateau. F. Recherches expérimentales sur la vision chez les arthropodes. Quat1889. rième partie. Mém. cour. Acad. roy. Belgique, t. XLIII, 91 pp.

Riley, C. F. C. Observations on the Ecology of Dragon-Fly Nymphs: Reactions 1912. to Light and Contact. Ann. Ent. Soc. Amer., Vol. V, No. 3, pp. 273-292.

Torelle, E. The Response of the Frog to Light. Amer. Jour. Physiol., Vol. 1903. IX, No. 6, pp. 466-488.

Verworn, M. General Physiology. Trans. by F. S. Lee. New York and London, 1899. $x v i+615 \mathrm{pp}$.

Ecological Laboratory, University of Illinois, January 31, 1913. 
